\title{
EDUCAÇÃO (FÍSICA) INFANTIL: TERRITÓRIO DE RELAÇÕES COMUNICATIVAS
}

\author{
MS. ELIANE GOMES DA SILVA \\ Mestre em Educação Física pela UFSC, doutoranda em Educação na USP e \\ Professora do Instituto Superior de Educação Orígenes Lessa (São Paulo - Brasil) \\ e-mail: nani.gomes@terra.com.br \\ DR. ELENOR KUNZ \\ Doutor em Ciências do Esporte pela Universidade de Hannover e \\ Professor Titular do Centro de Desportos da UFSC (Santa Catarina - Brasil) \\ e-mail: kunz@cds.ufsc.br
}

\section{DRA. LUCIA HELENA FERRAZ SANT'AGOSTINO \\ Doutora em Estruturas Ambientais Urbanas pela USP e professora aposentada da Faculdade de Arquitetura, Artes e Comunicação da UNESP (São Paulo - Brasil). \\ e-mail:santag@uol.com.br}

\begin{abstract}
RESUMO
Com base na Semiótica de C. S. Peirce, o objetivo deste estudo é refletir sobre as temáticas do modo específico de ser criança, das suas singularidades/alteridades e da produção de linguagem/signos como condições fundantes que configuram a prática pedagógica com crianças, compreendida como experiência vívida e relações comunicativas no fluxo das semioses. O método utilizado é o abdutivo/indutivo proposto por Peirce, pelo qual pudemos estabelecer relações específicas com a Concepção Dialógica do Movimento Humano - Se-Movimentar.
\end{abstract}

PALAVRAS-CHAVE: Educação fisica infantil; movimento humano; semiótica. 
Muitas pesquisas no âmbito da Educação Infantil, sobretudo as pautadas na Sociologia da Infância, têm concluído ser urgente a necessidade de se buscar uma práxis pedagógica que contemple o ponto de vista das crianças, considerando-as, verdadeiramente, como capazes, produtoras de saberes, de cultura, enfim, de linguagens.

Apesar da riqueza dessas contribuições, o que temos percebido, no entanto, é que a prática pedagógica com crianças, compreendida como experiência vívida, aberta e em fluxo, ainda tem ficado sem perscrutar.

No nosso entendimento, tal perspectiva só é possível ser efetivada se a dimensão das relações comunicativas for levada em conta, o que implica também a consideração de outras questões fundantes das condições que configuram essa prática - as singularidades/alteridades das crianças, o seu modo específico de ser e, em especial, o tema da produção de linguagem/signos.

A pergunta que guiou o desenvolvimento de nossa pesquisal foi: como é possível conceber uma prática pedagógica na Educação (Física) Infantil que realmente considere esses fatores e passe a dialogar com as crianças, de modo a efetivamente levar em conta seus repertórios/experiências singulares, assim como seus pontos de vista baseados, de fato, no princípio da alteridade 3 ?

\section{OBJETIVO E MÉTODO DE PESQUISA}

Neste ensaio ${ }^{4}$, nos dedicamos a travar um diálogo entre as teorias da Pedagogia da Educação Infantil e da Sociologia da Infância com a Semiótica de Charles Sanders Peirce, a fim de apresentar o nosso ponto de vista acerca da Educação (Física) Infantil, valendo-nos nesse momento da "concepção dialógica do movimento humano" trazida por Kunz (|99|, 200|).

Tal empreitada se fez necessária em função da diversidade de aspectos implicados na nossa pretensão de pesquisa: compreender, a partir do atrito entre

I. O presente trabalho não contou com apoio financeiro de nenhuma natureza para sua realização, nem houve conflitos de interesses para sua realização.

2. A utilização do termo "Educação (Física) Infantil", com parênteses, tem o propósito de indicar ao leitor que estamos suspendendo o entendimento de que a criança possui um lado "físico", que viabiliza o movimento, e outro "mental", que viabiliza as chamadas atividades cognitivas.

3. Por "alteridade", entendemos, como Peirce (1974, 1990), o Outro, as coisas e os seres com que nos defrontamos no Real (ou seja, o que é dado na existência) do mundo fenomênico (IBRI, I992).

4. Este artigo origina-se da dissertação de mestrado: GOMES-DA-SILVA, E. Educação (física) infantil: se-movimentar e significação. 2007. Dissertação (Mestrado em Educação Física) - Centro de Desportos, Universidade Federal de Santa Catarina, Florianópolis, 2007. 
essas teorias e nossa experiência prática na Educação (Física) Infantil, o fenômeno da infância na sua especificidade, da criança na sua singularidade/alteridade, bem como o processo educativo como prática singular e concreta, e, no nosso entendimento, verdadeiramente produtiva quando se efetiva como relações comunicativas.

$\bigcirc$ entrecruzamento dessas questões e das disciplinas científicas que podem ter a criança como objeto caracterizaram nosso "método" como um "vagar incerto" - entendimento que colhemos em Sant'Agostino ( 1995, p. 10) e que abriu inúmeros caminhos -, pois não pretendíamos "comprovar" uma ou outra teoria educacional, mas sim indagar/investigar a práxis infantil, junto ao concreto da experiência.

Adotamos, para isto, o método abdutivo/indutivo de investigação científica proposto por Charles Sanders Peirce. Tal método consiste:

\begin{abstract}
em estudar os fatos, a experiência, para buscar, a partir deles, delinear categorias interpretativas que os expliquem. Uma lógica heurística ou da hipótese, que supõe uma relação interrogativa com a experiência, que incorpora o "acaso", o fenômeno imprevisto, e permite uma forma nova de proceder na investigação científica, não mais apenas dedutiva, "comprovadora" de teorias já estabelecidas e codificadas (com fatos ou frequência interessadamente selecionados). Ao contrário, esta "ciência da descoberta" supõe que o pesquisador esteja 'colado' ao objeto de estudo, atento e vigilante, e conduzido por uma dúvida viva e real que prevê a possibilidade de criar uma fresta inovadora dentro do conhecimento teoricamente acumulado e fixado, e amplificá-lo (SANT'AGOSTINO, 200 I, p.25).
\end{abstract}

Assim, o recorte de nossa pesquisa priorizado neste texto é, especificamente, relacionar a perspectiva Semiótica peirciana com o Se-Movimentar ${ }^{5}$ Significativo na prática pedagógica da Educação (Física) Infantil, pois foi justamente o exercício de articular os fundamentos das duas perspectivas que nos permitiu vislumbrar esse âmbito como um "território" de relações comunicativas (Ferrara, 2002), ou seja, confronto concreto de alteridades.

\title{
A EXPERIÊNCIA E O SEU CARÁTER CÓSMICO
}

Para Peirce (1974), o pensamento é o domínio primeiro do Cosmos, e não restrito aos seres humanos, e o universo é pensamento, produção de informação

5. Kunz ( I99I, 200 I), baseado nos trabalhos dos holandeses Gordijn, Buytendijkk, Tamboer e, principalmente, do alemão A. Trebels, tem defendido o movimento humano a partir de sua inerente potencialidade dialógica, em cujo fundamento está a possibilidade da compreensão de temas como sensibilidade, percepção e intuição humana. Em tal concepção, que se opõe às abordagens que vêem o movimento humano de modo puramente biomecânico e em uma perspectiva empíricoanalítica, é levado em conta o ser humano que se movimenta, no nosso caso, a própria criança - e não o contrário, o movimento dela. 
ininterrupta e contínua; por conseguinte, constitui-se num processo evolutivo em constante crescimento (não ascendente, mas em rede) e diversificação. Evoluir é um processo contínuo da passagem da potência/possibilidade ao ato. Conforme Peirce, citado por Silveira:

\begin{abstract}
O pensamento não está necessariamente conexo a um cérebro. Ele aparece no trabalho das abelhas, dos cristais, e em meio ao mundo puramente físico; e ninguém mais pode duvidar que ele esteja realmente lá, tanto como estão as cores, as formas, etc. dos objetos [...] não somente o pensamento se encontra no mundo orgânico, mas nele se desenvolve (SILVEIRA, 2007, 25).
\end{abstract}

Esclarece-nos ainda esse autor que, jamais, para Peirce, o pensamento e o espírito aparecem como apanágio dos seres humanos,

muito menos de um sujeito que conhece. Mais do que considerar o pensamento uma propriedade decorrente de uma certa classe de seres, os seres é que pertenceriam ao domínio do pensamento, nele se encontrando em estágios de realização diferenciados (SILVEIRA, 2006, p. 5).

É recorrente, no campo acadêmico da Educação Infantil, a crítica ao adultocentrismo e o apelo a se levar, de fato, as crianças em conta. Com este propósito, buscamos, em Peirce, suporte para a difícil tarefa de nos libertar da responsabilidade de que somos apenas nós, adultos e professores, que conhecemos, e somos responsáveis pelo desenvolvimento da prática pedagógica com as crianças: o entendimento do Cosmos como pensamento, como mente, nos permite, de fato, pensar as crianças como alteridades que também pensam, produzem saberes e não, obrigatoriamente, somente recebem os saberes nossos, de adultos.

Também Kohan (2003) já nos alertou para a necessidade de, ao tratarmos de Educação Infantil, nos deslocarmos da excessiva referência dada ao fator conhecimento, para atentarmos ao fator pensamento. Esse autor, como Peirce, refere-se ao pensamento como condição do Ser, e não como uma capacidade localizada no cérebro humano. Por essa razão, Kohan argumenta que o conhecimento é algo que se supera, ou seja, que o pensamento faz e refaz. O pensamento não é algo passível de ser superado, ele é a possibilidade de continuar. Assim, o autor conclui que a infância é uma condição para pensar.

Isto implica dizer que devemos deslocar a concepção que temos de "infans" como o não-ser (impotente), o não-ter (capacidade, formação) e o não-saber (falar, produzir, criar), para concebê-la como uma potência, uma afirmação. As crianças são formadas social, histórica e culturalmente, é verdade, mas também são formadoras; elas são pensadas social, histórica e culturalmente, mas também elas próprias pensam. 
Ao nos relacionarmos com as crianças, se as percebermos simplesmente como submissas e receptoras dos saberes provenientes do mundo dos adultos, do enculturado e da lógica/estrutura verbal, deixaremos de entrever suas potencialidades enquanto sujeitos ativos e criativos, produtores de cultura, de linguagem/signos e, portanto, de conhecimentos.

\section{LINGUAGEM VERBAL E SEMIOSES}

Mesmo com os significativos avanços e descobertas no campo da Biologia, da Etologia e da Física e outros, ainda mantemos o hábito de acreditar que a representação linguística é aquela que constitui a racionalidade, ou seja, que o pensamento antropomórfico possui o domínio da racionalidade.

Nesse sentido, outro motivo - e este a nós muito caro - que nos leva a valorizar o pensamento peirciano, é que, neste, a linguagem verbal, a palavra, não é a matriz fundamental da produção humana de conhecimento.

A teoria peirciana alicerça-se na potência/possibilidade do universo fenomênico poder ser: daí, o prejuízo que pode advir do fato de se limitar as relações cognitivas apenas às formuladas por códigos já estabelecidos (especialmente, a linguagem verbal), o que leva a fechar o fluxo de possibilidades de comungar com outros Seres.

Contudo, vale o esclarecimento de que o pensamento peirciano não omite, de forma alguma, a riqueza da estrutura linguística. É nessa estrutura que nós, seres humanos, mais intensamente convivemos em nossa práxis, e, por isso, a linguagem verbal é também "especial", mas não no sentido de que possuiria a capacidade de retomar todos os outros gestos, todas as outras linguagens. A linguagem verbal é, para Peirce, mais um modo de manifestação semiótica, quer dizer, das semioses (processo de produção de signos/"linguagem").

Como argumenta Ibri ( 1992, p. I | 2), o pensamento peirciano nos traz preciosos esclarecimentos acerca do diferencial dessa perspectiva em relação a outras tendências filosóficas mais contemporâneas. $\bigcirc$ autor demonstra, com a metafísica de Peirce ${ }^{6}$, que a filosofia contemporânea recolheu-se ao aparentemente "seguro

6. A metafísica peirciana não tem teor transcendentalista; ao contrário, trata da realidade como mundo possível, das coisas como elas são. Quer dizer, é hipotético do mundo fenomenológico, mas fornece o substrato que sustenta nossa relação com o desejo de conhecer. "Real", para Peirce, é o mesmo que alter, geral e inteligível, "relativo à mente como quesito de equivalência entre ser e ser cognoscível" (PEIRCE apud IBRI, I 992, p. I 08), Assim, o vetor hipotético da metafísica tem sua origem na experiência, no confronto, no aqui-agora diante do cognoscível, e não do incognoscível. Tal ser cognoscível é dado fenomenologicamente na existência, o que implica dizer que "Quando admitimos que os limites do conhecer são os próprios limites do ser real, necessariamente devemos reconhecer uma dependência do âmbito epistêmico em relação ao âmbito metafísico" (IBRI, | 992, p. | | | - | |2). 
recinto da linguagem e sua lógica interior, numa atitude que se baseia no fato de que tudo o que possamos conhecer deve ser representado e, como tal, estar sujeito a uma gramática que enforma todo sistema de representações". $\bigcirc$ mundo e suas possibilidades evolucionárias deixam de ser o objeto - prossegue o autor - em favor da linguagem, restringindo boa parcela da Filosofia aos universos da sintaxe, da semântica e da chamada Lógica "formal".

Acredita Ibri ( 1 992), que o preço pago por algumas correntes filosóficas que se confinam à linguagem verbal como objeto de investigação parece ser muito alto:

Por um viés, elas parecem anestesiar-se na generalidade interior às representações, esquecendo-se de refletir sobre as condições positivas de possibilidade que licitam o estatuto geral da linguagem e, por conseguinte, do próprio pensamento, acarretando para seu projeto um teor nominalista, nos termos mais amplos das relações entre o particular e o geral. Por outro viés, esta espécie de transcendentalismo ao nível da linguagem parece estar, novamente, rodeada pelo espectro do incognoscível, pois saber do que virtualmente poderá estar contido na estrutura da representação pressupõe que possivelmente, alguma coisa possa não estar (IBRI 1992, p. 123).

vetor peirciano orienta-se no sentido oposto, continua o autor:

É a ordem do mundo que possibilita a ordem da representação; aquela é a realidade que torna possível o fenômeno da mediação. E o que estiver além de qualquer possibilidade de ser representado, não existe, conforme o quesito de identidade entre ser e ser cognoscível, evidenciado no Pragmatismo (idem).

\section{SE-MOVIMENTAR SIGNIFICATIVO}

Defendemos também o Se-Movimentar para a prática pedagógica da Educação infantil, que tem, de maneira ampla e íntegra, estreita relação com o entendimento peirciano de pensamento. Tal implica dizer que estamos tratando da base fundamental do Ser, isto é, de sua condição ontológica.

O Se-Movimentar e o pensamento não são, para nós, meros conceitos teóricos, passíveis de multiplicar preceitos técnicos, mas possuem dimensões

7. Peirce foi o precursor do Pragmatismo, mas convém esclarecer que seu pragmatismo sofreu muitos equívocos interpretativos no decorrer da história, distorcendo as intenções que lhes deram origem. Por exemplo, que o Pragmatismo é ação utilitária, é utilitarismo. Segundo Ibri ( 1992, p. 95), o Pragmatismo peirciano é localizável no início da cosmogênese, tomando forma nas relações de potência e ato "afirmando que uma potencialidade que assim permanece sem algum modo de definição, torna-se absolutamente inútil, sendo anulado pela própria vacuidade". Esta potencialidade transforma-se num continuum de possibilidades. Aqui está o teor da teoria indeterminista, ontológica e evolucionista de Peirce: "Cosmologia". 
ontológicas. A diferença que atribuímos a esses dois conceitos está no fato de o Se-Movimentar focar especificamente o ser humano na sua relação com o mundo. O prefixo "Se", que antecede "movimentar", atesta a presença do sujeito humano, ao passo que o conceito de "pensamento" (como Peirce o entende), extrapola, como já vimos, a esfera do humano. Contudo, confessamos que nos deparamos com muitas semelhanças e encontros entre esses conceitos.

É no Se-Movimentar que o Ser experiencia e, portanto, produz semioses, isto é, produz signos, o que, na esfera humana, também entendemos por expressividade.

Daqui buscarmos, no campo da Educação Física e especificamente da Educação (Física) Infantil o sujeito que se movimenta, e não o movimento do sujeito, do mesmo modo como Peirce entende que estamos em pensamento e não que os pensamentos estão em nós.

Quanto ao termo "linguagem", por ser amplamente vinculado ao conceito de língua e Linguística (como ciência), não nos parece termo apropriado para o entendimento de Linguagem como aqui a estamos concebendo. Se estamos entendendo, com base na cosmologia de Peirce, que todo Ser é cognoscível, não cabe continuar traduzindo em termos discursivos (sintaxe, semântica, fonema...) todos os sentidos expressivos do cognoscente. Todas as manifestações cósmicas têm sentidos próprios, como a língua, mas não apenas ela. Assim, é sugestão de Silveira (2006) que ousemos assumir essa "verdade"; como afirma Pignatari ( 1979 , p. 12), a semiótica peirciana "acaba de vez por todas com a ideia de que as coisas só adquirem significado quando traduzidas sob a forma de palavra".

Quando falamos em Linguagem, significamos semioses (o fluxo dos signos), pois, para a semiótica peirciana, a produção do conhecimento é sempre uma produção de signos - o pensamento é signo - e o significado de um signo é sempre um outro signo, um novo signo, de tal forma que o fluxo de pensamento dá-se em um fluxo incessante de signos, desde que a mente trabalha com associações ininterruptas, ad infinitum.

Por isso, acreditamos que a semiótica peirciana pode nos auxiliar a reencontrar a criança, quer dizer, ir ao encontro dela mesma e atentar às suas manifestações expressivas, ao seu ponto de vista, já que é este o objetivo que a prática pedagógica na Educação Infantil e a produção de conhecimento no campo da infância tanto vêm perseguindo. Em termos semióticos, podemos dizer que, talvez dessa maneira, possamos aprender - professores e pesquisadores - a controlar o nosso impulso interpretativo, que intercepta o fluxo das semioses, e assim permitir que, de fato, a criança se mostre e participe. 
"Segredos"8: este é o teor de nosso objeto de pesquisa. Cremos que muito pouco sabemos acerca da criança ela mesma, queremos dizer, nas suas manifestações empíricas/concretas, como alteridades. São as nossas concepções já conceituais que se interpõem como lentes mediatizadoras entre nós (pesquisadores/professores/ adultos) e com o que/como "abordamos"/interagimos na nossa prática pedagógica com as crianças.

Exemplo disso são os resultados da pesquisa de Arenhart (2003), com crianças que são filhos/as de participantes do "Movimento dos Sem Terra" (MST). A pesquisadora nos informa que, nas entrevistas que realizou com as crianças, elas tendiam rapidamente a responder com palavras comumente pronunciadas pelos participantes do MST - pais, professores etc. Contudo, as ações das crianças, quer dizer, seus gestos, sua expressão corporal (seu Se-movimentar), não se articulavam necessariamente com suas palavras, com seu suposto modo de pensar. As ações das crianças denotavam outros significados/sentidos, de modo que não havia um acordo entre o que as crianças respondiam/verbalizavam à pesquisadora - geralmente remetendo os sentidos das palavras para o futuro ("um futuro melhor") - e o que faziam no aqui-agora.

Desse exemplo depreendemos que, na verdade, as ações das crianças denotavam segredos que ainda não conseguimos interpretar nas pesquisas, bem como na prática pedagógica.

Aqui-agora, é este o sentido que importa às crianças. Não obstante seus repertórios/marcas do passado (muitas vezes de agressão, de cansaço pelo trabalho árduo, de tristezas, mas também de alegrias), elas são despreocupadas com o futuro. A criança se doa às possibilidades do presente.

Pois, se estamos em movimento/pensamento (e não o movimento ou o pensamento em nós), é no aqui-agora que podemos perceber a alteridade das crianças, ou melhor, de cada criança. Vale lembrar que é apenas a condição factual da relação, da interação e do confronto, permitidos pelo aqui-agora, que nos autoriza a referência ao termo cada criança?. Aí se encontram as alteridades.

É esse modo de ser criança, entregue ao aqui-agora, que nos alerta para o prejuízo que podemos causar ao tentarmos interpretá-la com base apenas na

8. Que, no entendimento dicionarizado, significa o que há de mais difícil numa arte ou ciência, conforme encontramos em: FERREIRA, A. B. H. Novo dicionário da língua portuguesa. 2. ed. Rio de Janeiro: Nova Fronteira, 1986.

9. Tal ressalva é necessária para não incorrermos em uma perspectiva individualista. 
estrutura linguística, traduzindo seu Se-Movimentar em um discurso previamente estruturado em sintaxe e semântica próprias da linguagem verbal. As diferentes manifestações expressivas (e agora estamos enfocando especificamente a esfera humana), significam "nelas mesmas" ${ }^{10}$, e não de maneira previamente subordinada à estrutura linguística.

Por isso Peirce tem como foco central de estudo os diferentes modos de ser, as diferentes formas de manifestação e transformação/evolução do Ser na experiência e no universo. Daí, a cosmologia ser o fundamento do seu pensamento.

Somos, assim, interpretantes do Universo, tanto quanto um cristal: o sujeito/ ser humano é uma interpretação cósmica/do universo tanto quanto os demais elementos. É deste entendimento, pois, que Peirce nos libera de ser o centro do mundo, do antropocentrismo.

No nosso entendimento, está no exercício de renunciar a nossos pré-conceitos a capacidade de atribuirmos direitos expressivos ao outro, de permitirmos que a criança seja esse outro, a alteridade, e não o incapaz. Muitas vezes, é pelo fato de a criança estar tão evidente a nós, estar tão perto, tão simples e resistente, que vamos perdendo, cada vez mais, a capacidade de enxergá-la e valorizá-la como expressão de uma singularidade. Talvez, o comodismo de nossas percepções diante do congestionamento de códigos e conceitos, nos impeça de enxergar isso que, de toda sorte, é muito claro, mas não óbvio.

Já a criança, embora nasça no seio de uma cultura estabelecida, ainda, acreditamos, não incorporou totalmente os significados consensuais determinantes da cultura/das representações. Ela é relativamente livre para expressar-se de modo espontâneo, intuitivo e pleno. Para o jogo da criação é necessário, diz Nietzsche (1999, p. 36), ser como uma criança: "A criança é a inocência, e o esquecimento, um novo começar, um brinquedo, uma roda que gira sobre si, um movimento, uma santa afirmação".

Na interpretação de Heller (2003) - que também busca reencontrar o Ser da experiência na educação musical -, nessa passagem de Nietzsche fica implícita a naturalidade da criança: é um brincar, um jogo. Ela não está, necessariamente, preocupada com o saber, com os valores, com as representações. Ela simplesmente é, deixa-se ser. Ela não está preocupada em armazenar conhecimentos, daí o esquecimento. A ação da criança não vem de um esforço, mas de um permitir (HELLER, 2003, p. I16).

Assim como a criança é o aqui-agora, ela também não se preocupa com o que ela tem ou o que ela é, como muitas vezes nós, adultos, nos preocupamos. A

10. O que não é a mesma coisa que ensimesmada, no sentido de isolada. 
criança entrega-se abertamente à vida e não se preocupa em possuir uma vida. Ela vive. Malraux (s.d., p. 25) afirma que o mundo para as crianças perde o seu peso, de tal forma que nele (no mundo) a criança se abandona, alheia à possibilidade de possuí-lo. Por isso este autor, ao falar da arte e do artista, reporta-se à criança, entendendo que, quando chamamos a criança de "artista", não é no sentido de possuir um talento, mas é o talento que possui a criança. Então, para Malraux, (s.d., p. 25), a criança substitui a maestria, a destreza, a capacidade pelo milagre: "Tudo se pode esperar da arte infantil - menos consciência e maestria: passa-se das suas imagens para a pintura como se passa das suas metáforas para Baudelaire. Essa arte morre com a infância".

"A essência da verdade reside em sua resistência em ser ignorada" (PEIRCE apud IBRI, I 992, p. 125). A sugestão de lbri ( I 992), ao finalizar seu ensaio com essas incisivas palavras de Peirce, é que estejamos dispostos a aprender. Parafraseando Peirce, diríamos que nós - professores e pesquisadores - insistimos em ignorar a sabedoria das crianças. Acrescentamos ainda: precisamos aprender a ouvir a revelação, atentar a ela, admirar o que é revelado, o que a criança nos mostra. Precisamos, na prática pedagógica, aprender a renunciar que achamos que sabemos mais. Mas só aprenderemos, continua lbri ( I 992), se de fato reconhecermos a força da experiência e da alteridade, emanadas estas de um entendimento cósmico.

Assim, já podemos inferir que há, sim, uma diferença entre ser adulto e ser criança e, que não se deve à faixa etária, maturação ou mesmo ao acúmulo de experiências. $\bigcirc$ que estamos considerando é que a criança, no encontro com o outro, possui - em relação aos adultos - maior disponibilidade para a entrega, para o envolvimento com o outro. Talvez possamos dizer que essa é uma condição tipicamente infantil, um modo de Ser criança no universo da experiência.

\section{CONCLUSÃO: ALTERIDADE COMO ALIMENTO DA EXPERIÊNCIA}

A base da teoria peirciana é a experiência vívida, isto é, só faz sentido em regime de experiência. Segundo Peirce, "Em filosofia, a experiência é o inteiro resultado cognitivo do viver"; e "Experiência é o curso de vida" (PEIRCE apud IBRI, 1992, p. 4).

Isso significa que a experiência é a própria alteridade se manifestando, produzindo, confrontando, evoluindo no universo. Reside aqui um entendimento cosmomórfico de alteridade, quer dizer, para além de um entendimento antropomórfico, para o qual alteridade tem a ver apenas com outro sujeito humano. Afinal, as relações que estabelecemos no nosso curso de vida não se limitam somente à esfera humana. 
Cabe, todavia, a ressalva de que não estamos negando que é no contato com outros sujeitos que nos reconhecemos como tal. $\bigcirc$ que propomos é renunciar às ideias de que "Ser" humano implica sobreposição de valores em relação a outros seres.

Almejamos uma prática pedagógica que seja realmente inclusiva e não pré-conceituosa. Reafirmamos a necessidade urgente da produção do conhecimento na área da Educação Infantil encarar, de frente, como se dá, de fato, o processo de mediação na prática pedagógica, para aproveitá-la como nutriente dessa prática.

Se entendemos que a semiose é a manifestação do Universo produzindo signos e se fazemos parte desse universo, sem pressupor hierarquização de valores, precisamos entender a mediação como relação entre signos, pois tudo pode ser signo. No nosso caso, tratando-se de crianças na dimensão da prática pedagógica, isto implica dizer que elas não devem ser entendidas com base em amostras da classe/categoria das crianças. Cada criança é, especialmente, aquela criança, precisa ser valorizada como tal, isto é, na sua singularidade. É este entendimento que nos impedirá de interceptar o fluxo interpretativo/produtivo que as crianças estabelecem no confronto com a prática pedagógica.

Para compreender isso em termos peircianos, resta-nos ainda, esclarecer que o objeto da semiótica é o objeto do afeto, logo, o que nos afeta. $\bigcirc$ que quer dizer que seu objeto é o que é comum (compartilhado); são as relações em comum, são os objetos articuláveis, enfim, são as mediações. Lembremos que objeto, para Peirce, não quer dizer "coisa", mas é, em uma explicação sumária, o que exige de nós uma conduta, ou seja, a produção de novos conhecimentos. Assim, no entendimento de produção de signos, também podemos entendê-lo como tomada de atitudes diante do objeto.

Em outras palavras, para Peirce, o processo de conhecimento é um processo de procura do objeto: pessoas, natureza, enfim, tudo que nos atrai, nos afeta e nos provoca a conhecer. Pois, para Peirce, objeto é objeto de uma conduta que, primeiramente, precisa ser admirado, interpretado, alcançado e aceito. Deste modo, norteamos nossa conduta no processo de conhecer algo, um objeto de desejo, uma alteridade. Nossa conduta é definida pelos objetos de nossos desejos; quer dizer, é o segredo que reside no objeto do nosso desejo que nos atrai/provoca. É o confronto com os objetos (de desejos) que determinam a conduta que tomamos. E a propriedade do objeto, esclarecemos, é a alteridade.

Nesse sentido, no âmbito especificamente da infância e da prática pedagógica, o Ser criança precisa ser concebido inicialmente como alteridade. É ela que precisamos 
conhecer. Como é ser criança, quais seus interesses, quais suas necessidades, o que ela sabe: eis o nosso objeto de desejo. Podemos até dizer que os seus desejos é que são os nossos desejos. É a partir deles que apresentamos os nossos. Quando admirada, a criança revela-se, mostra-se, aceita-se, e assim se admira (pois cada Ser é signo para si mesmo), e, por isso, também se transforma. Quer dizer, quando a criança tem a possibilidade de se mostrar e se conhecer, o que ela descobre é objeto para si própria, para sua admiração. É assim que ela produz signos, produz conhecimento, aprende, cria e se transforma.

Mas, quando uma criança não é admirada, não é provocada (porque somos também os desejos das crianças, elas querem nos conhecer, somos também admiráveis para elas, por isso se entregam a nós tão facilmente), nitidamente, ela não se mostra e também, facilmente, ela não se conhece. $\bigcirc$ que estamos dizendo é que não nos iludamos na suposição de que a criança não está se manifestando/ expressando quando não a admiramos; ela está, sim, expressando-se, mesmo que em tom silencioso (apenas por não serem viabilizados, permitidos por nós, não conseguimos percebê-los). $\bigcirc$ que fazer para escutá-la? Deixar que ela seja ela mesma e não o resultado das imposições dos nossos próprios desejos como adultos e/ou professores.

Não é, pois, o desejo do que queremos da criança que deve nos mover na prática pedagógica. É a própria criança que ilumina e atrai o nosso desejo pedagógico. Porém, que fique claro, é no confronto, no concreto, que tal relação se trava. Inspiremo-nos nas crianças. Recordemos de como elas choram quando, absortas em brincadeiras com outras crianças, suas mães lhes chamam para ir embora; isto é concreto, isto é experiência vívida.

Com efeito, é o confronto de alteridades que institui conhecimentos e aprendizagem. É preciso haver mediação, é preciso haver interação entre seres, e pertencer ao universo dos fenômenos. Só assim será concedido o direito de aprendizagem.

Assim, para que uma prática pedagógica na Educação (Física) Infantil se efetive propriamente como relações comunicativas, é preciso que criemos situações propícias a experiências, que possibilitemos espaço para a criança Se-Movimentar. Se quisermos ver a criança como criativa e participativa, é preciso que o professor seja seu interlocutor e não mediador no sentido que comumente entendemos - aquele que medeia entre o aluno e o conhecimento.

É tendo a oportunidade de Se-Movimentar, livre e espontaneamente, ou seja, a oportunidade de dialogar diretamente com o mundo, que a criança se mostra na relação comunicativa. 


\section{Children (Physical) Education: Space of Communicative Relations}

ABSTRACT: Based on C. S. Peirce Semiotics, the goal of this study is to reflect about the specific way of being a child, of his/hers singularities/alterities; also about the production of languages/signs as fundamental conditions which configure the pedagogical practice with children as a vivid experience and communicative relations in the flow of semioses. The method is abductive/inductive, as considered by C. S. Peirce, through which we could establish some specific relations with the Dialogical Conception of Human Movement: Self-movement.

KEYWORDS: Children physical education; human movement; semiotics.

\section{Educación (física) infantil: territorio de relaciones comunicativas}

RESUMEN: Basándose en la Semiótica de C. S. Peirce, el objetivo de éste estudio es reflexionar sobre las temáticas de la forma específica de ser niño, de sus singularidades/ alteridades; y sobre la producción de lenguaje/signos como condiciones fundantes que configuran la práctica pedagógica con niños, comprendida como experiencia vívida y relaciones comunicativas en el flujo de las semioses. El método utilizado es el abductivo / inductivo propuesto por Peirce, por lo cual pudimos establecer relaciones específicas con la Concepción Dialógica del Movimiento Humano: Se-Movimentar.

PALABRAS CLAVE: Educación física infantil; movimiento humano; semiótica.

\section{REFERÊNCIAS}

ARENHART, D. A mística, a luta e o trabalho na vida das crianças do Assentamento Conquista na Fronteira: significações e produções infantis. Dissertação (Mestrado em Educação) - Centro de Ciências da Educação, Universidade Federal de Santa Catarina, Florianópolis, 2003.

FERRARA, L. D. Entre a comunicação e a semiótica, o mundo. Ghrebh-Revista de Comunicação, Cultura e Mídia, São Paulo, v. I , n. 5, p. I-7, maio 2004.

HELLER, A. A. Ritmo, motricidade, expressão: o tempo vivido na música. Dissertação (Mestrado em Educação) - Centro de Ciências da Educação, Universidade Federal de Santa Catarina, 2003.

IBRI, I. A. Kósmos Noetós: a arquitetura metafísica de Charles S. Peirce. São Paulo: Perspectiva, Hólon, 1992.

KOHAN, W. O. Infância: entre educação e filosofia. Belo Horizonte: Autêntica, 2003.

KUNZ, E. Educação Física: ensino e mudança. ljuí: Ed. Unijuí, 1991.

KUNZ, E. Transformação didático-pedagógica do esporte. 4. ed. ljuí: Ed. Unijuí, 200 I. 
MALRAUX, A. As vozes do silêncio 2: a criação artística e o preço do absoluto. Lisboa: Edição "Livros do Brasil", s.d.

NIETZSCHE, F. Assim falou Zaratustra. São Paulo: Martin Claret, 1999.

PEIRCE, C. S. Escritos coligidos. São Paulo, Abril Cultural, 1974. (Os Pensadores, v. 36)

PIGNATARI, D. Semiótica e literatura. São Paulo: Cortez \& Moraes, 1979.

SANT'AGOSTINO, L. H. F. Bauru, chão-de-passagem: entreposto de valores na rota AtlânticoPacífico. Disssertação (Mestrado em Estruturas Ambientais Urbanas) - Faculdade de Arquitetura e Urbanismo, Universidade de São Paulo, São Paulo, 1995.

SANT'AGOSTINO, L. H. F. Rumo ao concreto. Tese (Doutorado em Estruturas Ambientais Urbanas) - Faculdade de Arquitetura e Urbanismo, USP, São Paulo, 2001.

SILVEIRA, L. F. B. da. Curso de semiótica geral. São Paulo: Quartier Latin, 2007.

SILVEIRA, L. F. B. da. Curso introdutório de semiótica. Marília: Faculdade de Filosofia e Ciências, Unesp, 2006.

Recebido: 16 set. 2009

Aprovado: 02 jun. 2010

Endereço para correspondência:

ELIANE GOMES DA SILVA

Faculdade Orígenes Lessa.

Rodovia Onsy Matheus, Km. 108.

CEP: I 8683-900 - Lençois Paulista, SP - Brasil

Telefone: (I 4) 32693939

URL da Homepage: http://www.facol.br 